\title{
Uma análise histórico-geográfica da importância
do rio Beberibe para o abastecimento de água da Região Metropolitana do Recife
}

\author{
A historical and geographical analysis of the importance of Beberibe \\ River for the water supply of the Metropolitan Region of Recife \\ Un análisis histórico y geográfico de la importancia del río Beberibe \\ para el suministro de agua de la Región Metropolitana de Recife
}

Hernani Loebler Campos Universidade Federal de Pernambuco (UFPE) Recife, Brasil hernaniloebler@gmail.com

Soênia Maria Pacheco Universidade Federal de Pernambuco (UFPE) Recife, Brasil smpcap@yahoo.com.br

\footnotetext{
Resumo - Este artigo tem como objetivo apresentar algumas considerações sobre o rio Beberibe e sua importância histórico-geográfica para 0 abastecimento de água da Região Metropolitana do Recife. Neste texto, são tratados os principais projetos públicos e privados de fornecimento de água, desde a fundação da cidade de Olinda, até os dias atuais, destacando-se a relação entre o adensamento populacional e as consequências para o manancial Beberibe.
}
Abstract - The objective of this article is to present some considerations on the river Beberibe and its historical and geographical importance for the water supply for the Metropolitan Area of Recife. In this text, the main public and private water supply projects are reviewed, from the foundation of the Olinda city to the present day, with emphasis on the relationship between the increase in population density and consequences for the Beberibe source.

Resumen — Este artículo tiene como objetivo presentar algunas consideraciones sobre el río Beberibe y su importancia histórica y geográfica para el suministro de agua en la región metropolitana de Recife. Este estudio analiza los principales proyectos públicos y privados de abastecimiento de agua desde la fundación de la ciudad de Olinda hasta nuestros días, destacando la relación entre la densidad de población y las consecuencias para la manantial Beberibe.

\footnotetext{
Palavras Chaves: Região Metropolitana do Recife, Bacia hidrográfica, Abastecimento de água, Gestão Keywords: Metropolitan Region of Recife, Drainage basin, Water supply, Management

Palabras Claves: Región Metropolitana de Recife, Cuenca hidrográfica, Abastecimiento de agua, Gestión
} 


\section{ASPECTOS GERAIS DA BACIA HIDROGRÁFICA DO BEBERIBE}

Com cerca de 75,45 $\mathrm{km}^{2}$ de área, a bacia do Beberibe encontra-se na Região Nordeste do Brasil, no estadode Pernambuco, totalmente inserida na Região Metropolitana do Recife (RMR), envolvendo parte dos municípios do Recife (54 km2), de Olinda (14 km2) e de Camaragibe $(7,45 \mathrm{~km} 2)$. Em valores percentuais, esses municípios envolvem 64,51\% (Recife), 21,29\% (Olinda) e 14,19\% (Camaragibe) da RMR (Figura 1).
O rio Beberibe nasce nas terras do antigo engenho Pau Ferro, no município do Recife, à altitude de 130 metros, percorrendo um total de $31 \mathrm{~km}$ até o Oceano Atlântico, sendo formado pela junção dos rios Pacas $\left(7,42 \mathrm{~km}^{2}\right)$ e Araçá $\left(7,34 \mathrm{~km}^{2}\right)$. Somente após esta confluência é que passa a receber a denominação de Beberibe. Seus principais afluentes pela margem direita são o rio Morno $\left(10,15 \mathrm{~km}^{2}\right)$, que por sua vez recebe, também, as águas do rio dos Macacos $\left(8,73 \mathrm{~km}^{2}\right)$ e o canal Vasco da Gama $\left(13,35 \mathrm{~km}^{2}\right)$ ou canal do Arruda. Pela margem esquerda, o riacho Lava Tripa $\left(3,46 \mathrm{~km}^{2}\right)$, também conhecido como córrego do Abacaxi, e o canal da Malária $\left(4,3 \mathrm{~km}^{2}\right)$ são os seus afluentes mais importantes. Ao encontrar o Malária, o Beberibe abandona sua direção geral oeste-leste e toma o sentido sul, margeia o “istmo de Olinda” e, finalmente, lança-se em uma foz conjunta com o Capibaribe no oceano Atlântico Atlântico ${ }^{1}$

(Figura 2)

Figura 2. Mapa da rede de drenagem do rio Beberibe

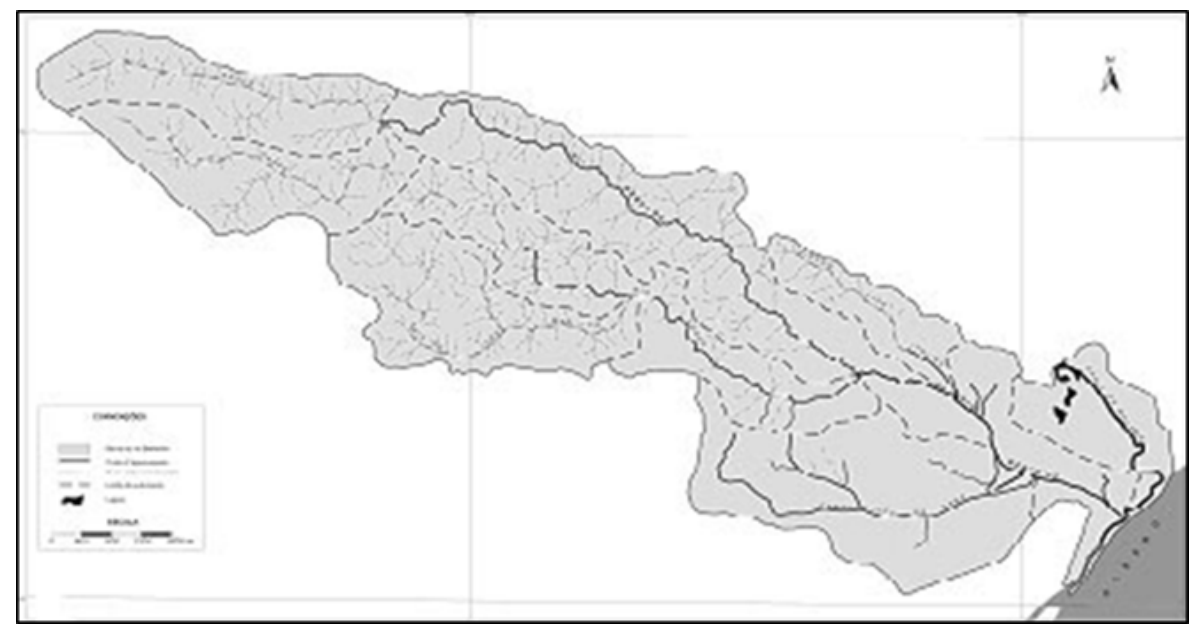

Fonte: Campos, 2003.

Fonte: Campos, 2003.

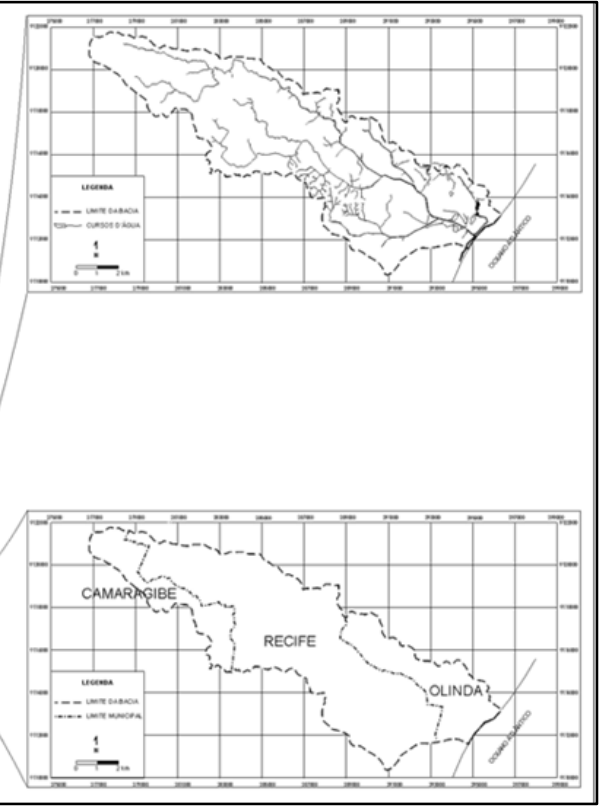
.

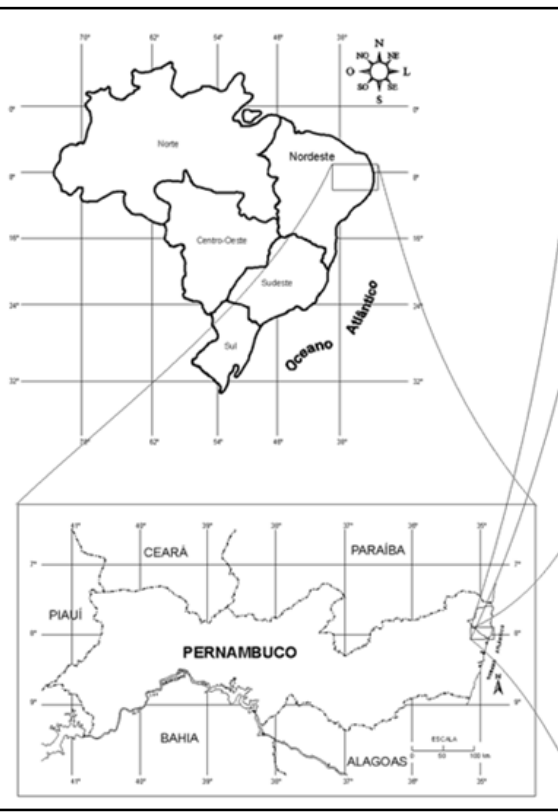


O RIO BEBERIBE E OS PRIMÓRDIOS DO ABASTECIMENTO DE ÁGUA EM RECIFE E OLINDA

Até meados do século XIX, o rio Beberibe foi a principal alternativa de abastecimento de água do Recife e de Olinda. O local escolhido para a fundação do povoado de Olinda, capital da capitania de Pernambuco, por Duarte Coelho Pereira, em março de 1535, foi uma colina situada na margem esquerda do rio Beberibe, de onde poderia se observar o estuário formado por este rio e pelo Capibaribe ${ }^{2}$.

Costa $^{3}$ verifica que, em 1542, Duarte Coelho ordenou que se construíssem os primeiros engenhos de açúcar na já próspera vila de Olinda. Surgiu, então, fundado por Jerônimo de Albuquerque, cunhado do donatário, em uma grande data de terra, de doação donatarial a título de sesmaria, o engenho Nossa Senhora da Ajuda, primeira fábrica de açúcar erguida em Pernambuco (Figura 3). Foi a partir desse engenho, situado a três quilômetros do cais do Varadouro, subindo o rio Beberibe, onde atualmente encontramos o bairro de Peixinhos, que se retirava naturalmente água para o abastecimento de Olinda.

Figura 3. Engenho Nossa Senhora da Ajuda

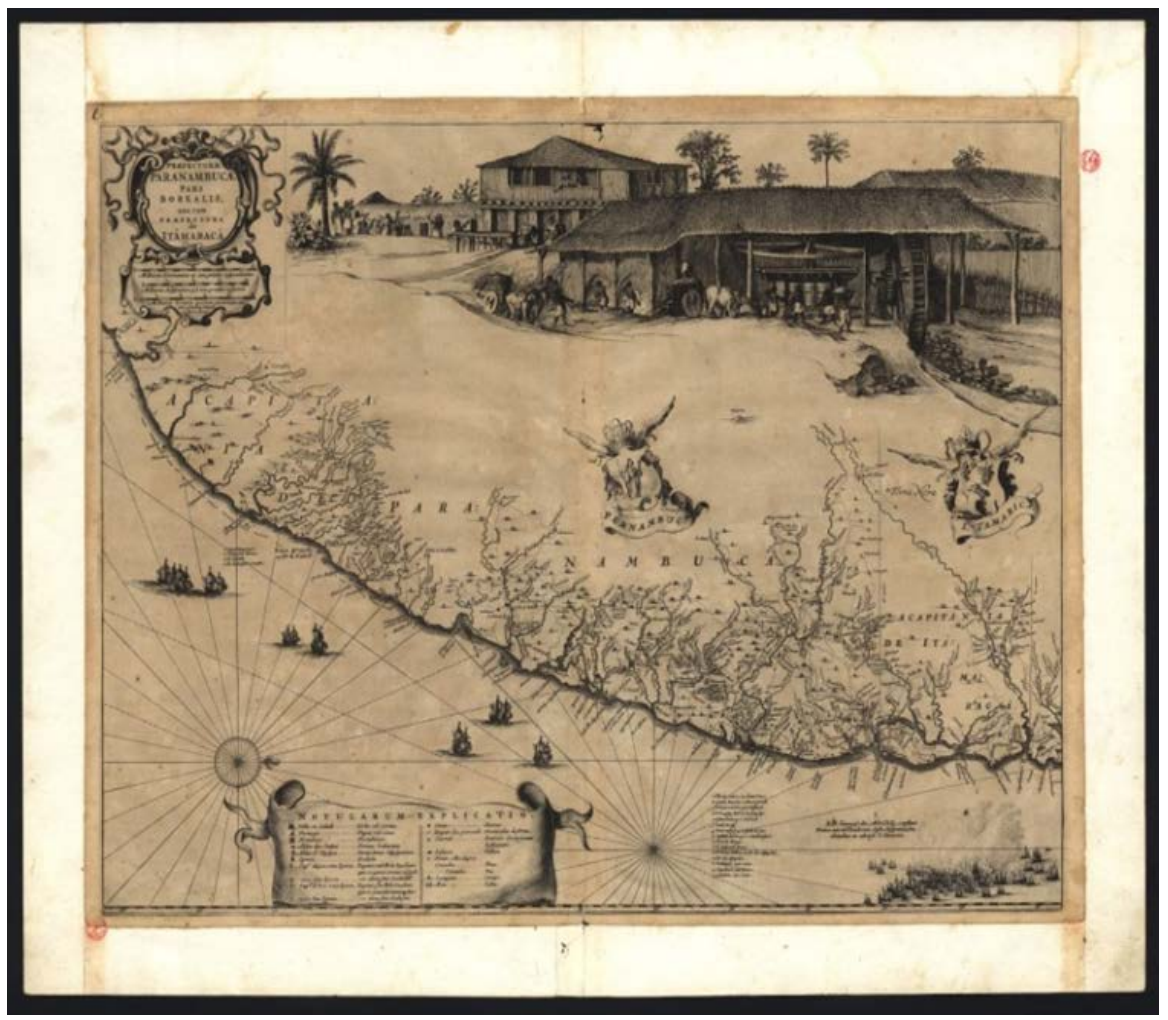

Fonte: http://engenhosdepernambuco.blogspot.com.br/2012/06/engenho-nossa-senhora-da-ajuda-velho-e.html
A intensa procura do açúcar pela Europa e seu lucrativo comércio ocasionaram ampliação dos canaviais e a instalação de vários engenhos nos baixos cursos dos rios Beberibe e Capibaribe. A fixação desses engenhos, somada a vinda de escravos africanos, que substituíram o trabalho indígena, e a intensificação da migração portuguesa são fatores que certamente viabilizaram um rápido crescimento do povoamento pelo baixo vale desses rios ${ }^{4}$.

Com o desenvolvimento da atividade açucareira e, consequentemente, a expansão urbana de Olinda, e a criação da vila do Recife, o problema do abastecimento de água agravou-se. Em Olinda, como a retirada natural das águas do rio Beberibe não era suficiente para o consumo da crescente população, nas propriedades existiam cacimbas que forneciam água potável ou salobra. Para o público havia fontes que eram vulgarmente denominadas de bicas, como a do Rosário, a bica dos Quatro Cantos (Figura 4), a de São Pedro, a do Poço do Conselho e a Cacimba dos Milagres ${ }^{5}$.

Na vila do Recife, a população era abastecida de água por um sistema primitivo e realizado por canoas que retiravam água do Beberibe e do Capibaribe no trecho em que os mesmos não sofriam a influência da maré. A planície do Recife é muito baixa e por ocasião das marés altas o mar invade o leito dos rios, tornando a água salobra ${ }^{6}$. Freyre fazia referência a essas canoas:

"A canoa esteve por muito tempo ligada a paisagem de Olinda e dos seus arredores. Era principalmente de canoa que se viajava de Olinda ao Recife. A canoa foi um meio tão aristocrático de transporte por mar como o palanquim de transporte por terra. Algumas canoas eram adornadas com figuras na proa: tinham camarins na popa. Camarins ás vezes forrados de veludo, como palanquins dos olindenses ricos. Mas havia também canoas proletárias. Canoas de pesca. Canoas para o transporte de água. Canoas para mudança de trastes. Canoas para carregar pedra e tijolo" 7 .

\footnotetext{
${ }^{4}$ Costa, 1982.

${ }^{5}$ Costa, 1983

${ }^{6}$ Campos, 1991.

${ }^{7}$ Freyre, 1944, 59.
}

\footnotetext{
${ }^{2}$ Andrade, 1979.

${ }^{3}$ Costa, 1983.
} 
Figura 4. Bica dos Quatro Cantos, na cidade de Olinda

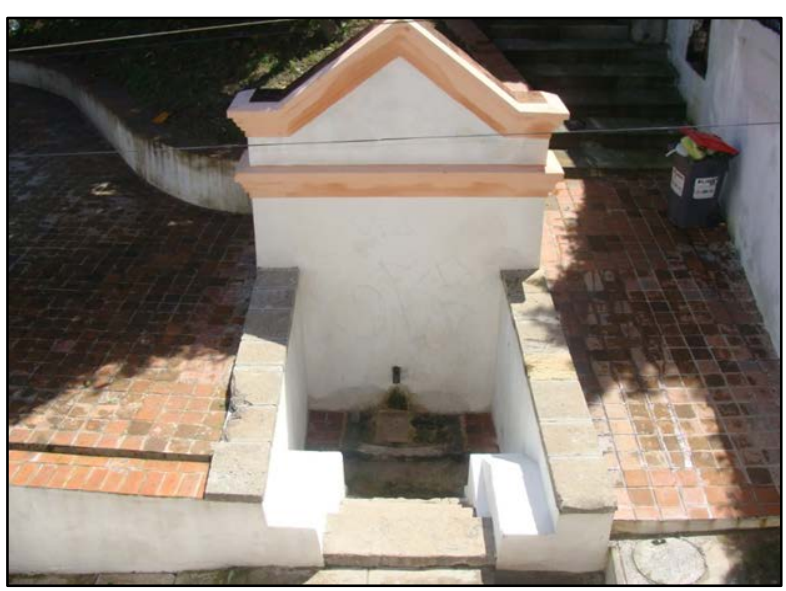

Fonte: https://casasdopatrimoniope.wordpress.com/2011/05/09/concluida-obrade-recuperacao-da-bica-dos-quatro-cantos/

As águas do Beberibe que abasteciam a vila do Recife eram retiradas na ponte do Varadouro, em Olinda, e conduzidas, margeando o istmo, por grandes canoas especialmente construídas para esse fim. Gomes ${ }^{8}$ destaca que o istmo representou, no período colonial, o principal meio de acesso para viabilização de interesses sociais, econômicos e militares, entre a vila de Olinda e a península de Santelmo, atual bairro do Recife (Figura 5) .

De acordo com Costa ${ }^{9}$, as águas do rio Beberibe eram de boa qualidade, no entanto, elas se tornavam inadequadas ao uso humano, pois as canoas eram inapropriadas para o seu transporte, bem como os seus condutores permitiam que indivíduos nelas se banhassem, fato não desconhecido pela população, que reivindicava a construção de um encanamento.

Do rio Capibaribe, as águas eram apanhadas no lugar denominado Cabocó, próximo à povoação do Monteiro, hoje, bairro do Monteiro (Figura 6), também transportadas em canoas e vendidas no Recife. Em 1630, com a chegada dos holandeses e sua fixação nessa cidade, estes, observando a precariedade do sistema de abastecimento de água, e por se encontrarem sitiados, rapidamente trataram de abrir cacimbas na ilha de Antônio Vaz. No entanto, as águas aí retiradas só serviam para lavar casas ${ }^{10}$.
No ano de 1684 foi construída a barragem do Varadouro que represava as águas do Beberibe na altura de Olinda, formando-se, então, um grande lago a montante da mesma. Andrade ${ }^{11}$ observa que até começos do século XVIII o rio Beberibe desaguava no Varadouro, talvez por ainda correr num leito primitivo, talvez por, a maneira dos "furos" amazônicos, por ali emitir parte da descarga antes de recuperá-la a jusante, no estuário final.

A barragem foi levantada durante o governo de Souto Maior, concluída em 1685, e sua função principal era salvar as águas do Beberibe do fluxo das marés, tornando-as, dessa forma, adequadas para o consumo. Em verdade, Pitta afirma que "todo o século XVIII andaria cheio de apologias a dilatada e formosa ponte, ao pé da qual se podia estar a um tempo nadando na água salgada, e tomando a doce" ${ }^{, 12}$.

A ponte atravessava o rio, em linha reta, com sua face leste fronteira à ladeira do Varadouro, partindo de um cais ou muralha de 28,6 metros de extensão. Media 33 metros de comprimento sobre 6,6 metros de largura, e constava de três arcos, tendo o do centro altura e

Figura 5. O istmo de ligação entre Olinda e Recife

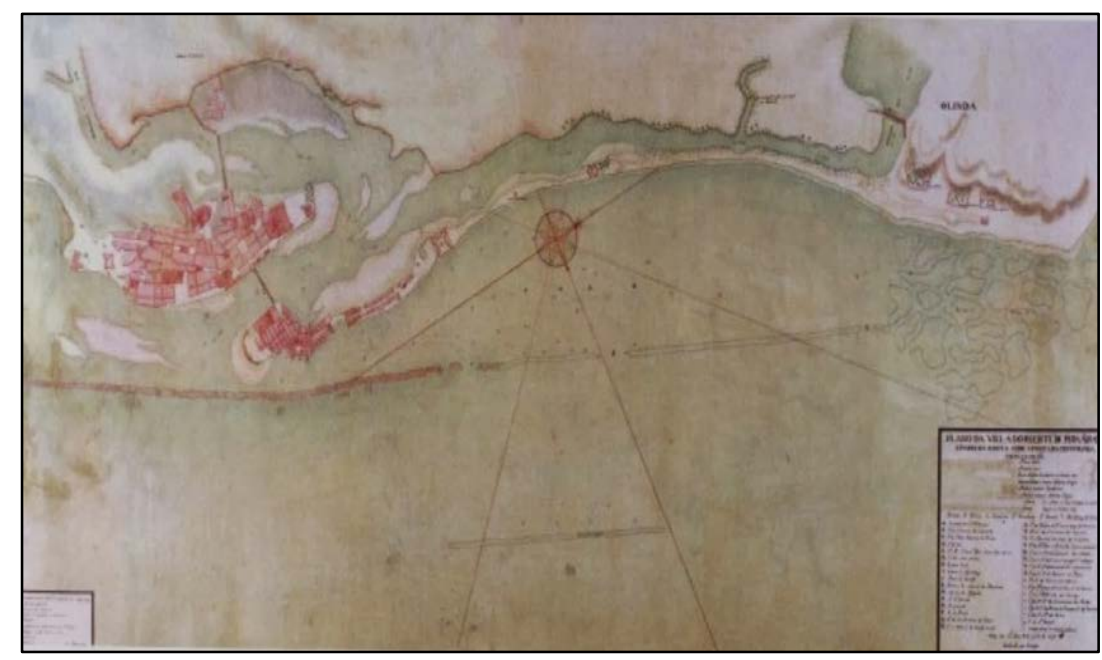

Fonte: http://bairrodorecife.blogspot.com.br/2014/01/bairro-do-recife-uma-ilha-por-acidente.html

largura superiores aos outros dois e, no alto, um vistoso cruzeiro (Figura 7).

Pelas suas dezoito bocas que despejavam água por fora do muro, a população olindense abastecia-se de água, já que, sobretudo nos meses de estio, as bicas e cacimbas da vila não eram, de maneira alguma, suficientes (Figura 8). Entretanto, no dizer de Andrade, "a represa do Varadouro veio a constituir mais um pomo

\footnotetext{
${ }^{11}$ Andrade, 1979.

${ }^{12}$ Pita, 1950, 80.
}

\footnotetext{
${ }^{8}$ Gomes, 1997.

9 Costa, 1983.

10 Mello, 1988.
} 
de discórdia entre o Recife e Olinda, engendrando disputas que iriam durar mais de cem anos” ${ }^{\text {. }}$.

Os desentendimentos entre recifenses e olindenses foram agravados pelo fato de que, quando havia uma ponte em lugar da barragem, as canoas do Recife

Figura 6. Mapa do bairro do Monteiro no Recife

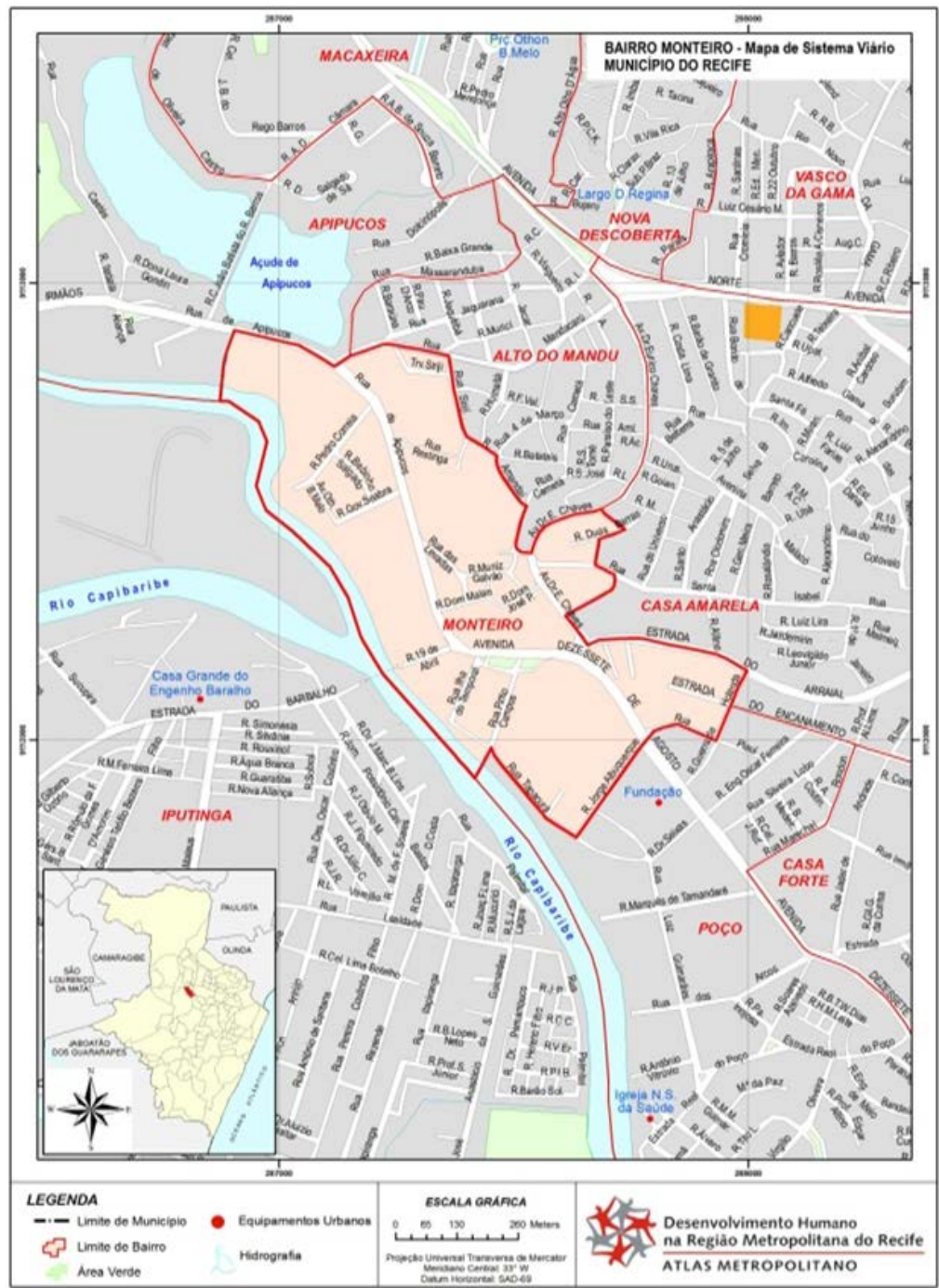

Fonte: http://www2.recife.pe.gov.br/wp-content/uploads/MONTEIRO.jpg

podiam subir o rio e se abastecer, não só de água, mas também de lenha. Com o tapamento da ponte essa operação tornou-se inviável. Por outro lado, os recifenses não permitiam que seus canoeiros retirassem água dos canos da Barragem do Varadouro, pois com o represamento, afirmava o povo do Recife, as águas tornaram-se infectas e o ar irrespirável pela exalação de vapores nocivos oriundos da barragem que provocaram muitos males à população ${ }^{14}$.

\footnotetext{
13 Andrade, 1969, 143.

14 Costa, 1983.
}

Na realidade, havia um pânico geral ocasionado pela informação de que a água represada era a responsável por esses males. Andrade ${ }^{15}$ verifica que a população recifense responsabilizava a construção da barragem do Beberibe pela podridão do ar e das águas de consumo. No entanto, os males referidos não seriam ocasionados pelo represamento do Beberibe, mas pela ocorrência da malária endêmica e da febre amarela que se repetiam constantemente dizimando parte das populações do Recife e de Olinda. Ainda, segundo o mesmo autor, “a pestilência havia irrompido no Recife em 1685 e ainda em 1689 não agredira Olinda, cuja frouxa densidade habitacional, nunca ofereceria condições de infestação iguais às do Recife e Santo Antônio, acotovelados em reduzido espaço urbano" ${ }^{16}$.

Costa comenta que, segundo o médico Simão Pinheiro Morão, escrevendo no Recife, em 1677, portanto antes da construção da barragem, classificou precisamente "as três ou quatro espécies de febres podres, que nestas capitanias se acham, que são a terçã doble, a terçã simples, e algumas posto que raras vezes, a quartã”.17. Entretanto, pressionado pela população recifense, o governador Souto Maior mandou destruir a represa, o que causou grande revolta na população olindense. $\mathrm{O}$ paredão foi destruído em 1686 e causou, daí por diante, uma luta obstinada de Olinda para a sua reconstrução e ao mesmo tempo incansáveis promoções dos recifenses para novamente pô-lo abaixo.

Em 1711 a população olindense se rebelou e restabeleceu a barragem. O Conselho Ultramarino Português não aceitou tal rebeldia e mandou desfazê-la.

Em 1714 foi feita uma nova tentativa para a restauração do açude. Andrade ${ }^{18}$ observa que não tinha fundamento responsabilizar a represa do Varadouro pela pestilência, pois desde 1711, quando do seu soerguimento, os males já não assolavam a população como em tempos passados. Quanto à recusa dos recifenses de se abastecerem do açude era de se estranhar, pois o mesmo

\footnotetext{
${ }^{15}$ Andrade, 1969.

${ }^{16}$ Andrade, 1969, 133.

${ }^{17}$ Costa, 1983, 204

${ }^{18}$ Andrade, 1969.
} 
facilitava o pronto abastecimento. Além disso, o açude, mantido sempre cheio graças à parcimônia das torneiras, criava grande abundância de peixes e crustáceos. Essa era outra razão por que os olindenses se empenhavam em conservar tapado o rio. As reivindicações desta feita foram atendidas e a tapagem refeita.

Figura 7. Parte central superior da ponte do Varadouro do

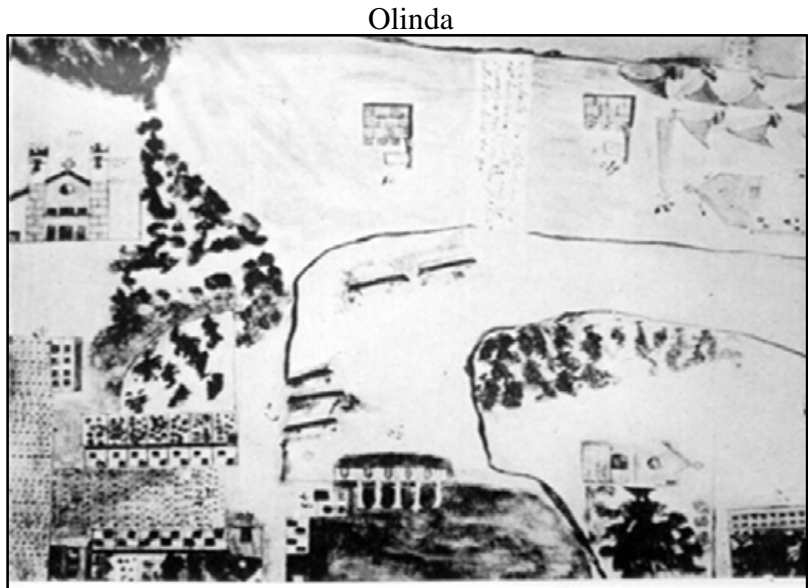

Fonte: Campos, 1991

Finalmente, em 1856 a barragem foi demolida e substituída por uma ponte de ferro, construída pela extinta Fundição Aurora. Esta ponte perdurou até 1914, quando foi construída outra, de resistência ao trânsito dos bondes elétricos.

Figura 8 - Convento dos Frades do Desterro Religioso de Santa Thereza (A) e a Ponte do Varadouro, onde corre pelas bicas água de beber sobre a salgada (B)

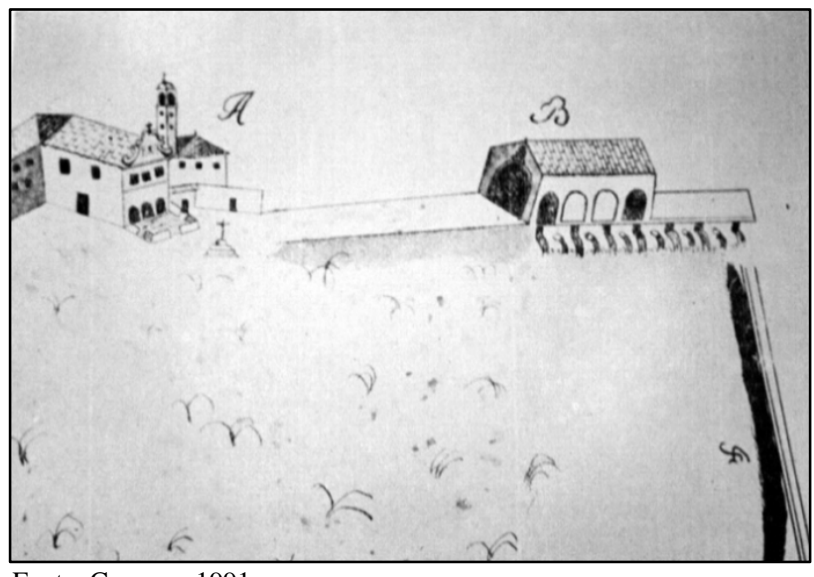

Fonte: Campos, 1991

A demolição definitiva foi ordenada pelo então governador Conde da Boa Vista, que também determinou a drenagem da área anteriormente alagada, trabalho esse realizado precariamente, e sua posterior ocupação por atividades agrícolas.

O transporte de água em canoas provocou uma intensa comercialização do produto envolvendo um forte capital. Na tentativa, por parte das autoridades, de se evitar esse comércio e de se ampliar o papel do Beberibe como manancial, vários projetos surgiram com a finalidade de trazer por terra a água para o consumo da população. No entanto, vários desses projetos não foram bem sucedidos por motivos os mais diversos, entre eles o fato das águas puxadas do rio Beberibe correrem em terrenos arenosos, havendo, então, sua infiltração; ou por motivo de as águas passarem em áreas onde a presença do gado bovino tornavam-nas inadequadas para o consumo.

Outros projetos não tiveram solução de continuidade. Estudos realizados na segunda metade do século XVIII por José Fernandes Portugal, José Joaquim de Santana e Eusébio da Costa Assunção, tinham como objetivo viabilizar o abastecimento de água da cidade de Olinda e da vila do Recife. O manancial escolhido foi o rio Beberibe no lugar denominado Sítio do Beringuel, que tinha uma altura de 6 metros em relação ao Varadouro, altura essa suficiente para abastecer Olinda e Recife. A água seria conduzida até Olinda por um canal aberto na terra e em aqueduto de arcaria com encanamento de barro para manter a água mais fresca, até a vila do Recife. Outro projeto que não teve prosseguimento foi um estudo realizado em 1821, por Conrado Niemeyer. O engenheiro idealizou um projeto aproveitando a represa do rio Beberibe para tornar sua navegação contínua sem a espera das marés, e a construção de um açude de comportas, em Olinda, que receberia as águas do Beberibe e daí conduzidas até o Recife $^{19}$.

\section{O USO DAS ÁGUAS DO BEBERIBE NOS SÉCULOS XIX E XX}

Na primeira metade do século XIX, a então cidade do Recife experimentou uma fase de grande crescimento e modernização, após a Abertura dos Portos às Nações Amigas, quando, então, os comerciantes brasileiros puderam comerciar diretamente com outros países notadamente a Inglaterra. Em face desse crescimento foi necessário organizar um sistema de abastecimento de água. Para tanto, Pinto afirma que em 1835 foi criada a Beberibe Water Company. Nas suas palavras:

"Entre os serviços públicos prestados a Pernambuco com os capitais e por administradores ingleses figura o abastecimento de água potável, feito pela Beberibe Water Company, que contava entre os seus engenheiros E. Brotherhood. Foi também o engenheiro Oswald Brown que traçou os planos e dirigiu os serviços de construção das galerias subterrâneas do Açude da Prata”20.

\footnotetext{
${ }^{19}$ Costa, 1983.

${ }^{20}$ Pinto,1949, 61.
} 
Em junho de 1838 foi autorizada a contratação de pessoas para formar uma companhia de fornecimento de água potável à cidade do Recife, água essa que poderia ser extraída do riacho do Prata, açude do Monteiro, açude de Apipucos, ou do rio Beberibe. Bento José Fernandes, Francisco Sérgio de Matos e Manuel Coelho Cintra requereram e conseguiram autorização para formar a empresa que se denominou Companhia do Beberibe, pois uma das cláusulas do contrato referendava que as águas destinadas ao abastecimento seriam extraídas do rio Beberibe. No entanto, em 1841 houve modificações no contrato e a mais significativa se referia ao fato de que a Companhia poderia extrair a água de onde mais lhe conviesse, desde que a mesma fosse potável e de boa qualidade.

Vários projetos de abastecimento de água foram então desenvolvidos e apresentados. Dentre eles pode-se citar o Projeto para o Encanamento das Águas do Rio Beberibe ao Centro da Cidade do Recife, de autoria do engenheiro francês Júlio Boyer; Memória e Projeto sobre o Encanamento de Águas Potáveis para a Cidade do Recife, organizado pelos engenheiros Jacob de Niemeyer e Pedro de Alcântara Bellegarde e, finalmente, o Projeto de Abastecimento de Água para o Recife, tratando da dissecação do pântano de Olinda e canalização do rio Beberibe, apresentado pelos engenheiros franceses Luís Leger Vauthier, Pedro Victor Boulitreu e Henrique Augusto Millet. O projeto escolhido pela Companhia do Beberibe foi o de Niemeyer e Bellegarde e, entre os mananciais, o que apresentou melhores condições foi o açude do Prata ${ }^{21}$.

O riacho do Prata nasce a $12 \mathrm{~km}$ a noroeste do Recife e logo após a sua nascente ele se avoluma e forma o açude do Prata. Os fatores que levaram a Companhia em questão a indicar o manancial do Prata foram a sua altitude, situado a dez metros acima dos pontos mais altos da cidade do Recife, a qualidade de suas águas sempre cristalinas e puras, além da regularidade de seu volume, proporcionando, em média, 4.000 metros cúbicos de água por segundo.

Com a destruição da barragem do Varadouro em 1856, os olindenses passaram a contar apenas com as fontes públicas e particulares, o que não era suficiente para o abastecimento de água da cidade. Foram, então, realizadas várias tentativas de se extrair água diretamente do rio Beberibe. A primeira delas se deu em 1856, com a abertura de um canal em linha reta que ia do rio Beberibe, no sítio dos Craveiros, até o Varadouro. No entanto, tal tentativa não teve êxito.

A população olindense, mirando-se no exemplo do Recife, com a criação da Companhia do Beberibe, exigiu uma melhor organização no seu abastecimento de água. Para tanto, foi instituída uma empresa denominada Companhia de Santa Thereza, fundada na cidade do Recife, por Claudino Coelho Leal, tendo sido os seus estatutos aprovados pelo governo Imperial em 10 de setembro de 1870 . Sua principal finalidade era abastecer de água potável, luz e força por eletricidade a cidade de Olinda, bem como seus subúrbios, tendo sua sede na mesma cidade.

A Companhia deu início aos seus trabalhos em 04 de agosto de 1872, inaugurando um chafariz no Varadouro e posteriormente outros em lugares diversos. As águas que abasteciam os chafarizes eram retiradas, através de canalização, do rio Beberibe na localidade chamada de Cumbe, cerca de $1 \mathrm{~km}$ acima da ponte da povoação de Beberibe. No entanto, a Companhia nunca serviu satisfatoriamente a população. Com o interesse de monopolizar a distribuição de água, a empresa tratou de destruir ou inutilizar as antigas fontes e poços públicos de abastecimento de água à cidade, tomando tal atitude sem a menor oposição dos poderes públicos. Foi fechada a bica do Rosário, destruída a dos Quatro Cantos, entulhada a cacimba Poço do Conselho e murada a dos Milagres, provocando tristeza e revolta, já que as fontes públicas de Olinda eram consideradas propriedades de seu povo.

Em 1910, a Comissão de Saneamento do Recife elaborou uma série de estudos com o objetivo de aumentar a oferta de água para a sua população. Em 1911, o engenheiro chefe da referida comissão, Dr. Saturnino Rodrigues de Brito, em trabalho conjunto com o eminente médico e engenheiro francês Dr. Imbeaux realizaram uma série de visitas aos vários mananciais abastecedores do Recife. Ao final dessas visitas foi dado um parecer apontando as possíveis soluções para a questão.

Uma das soluções destacava a possibilidade de se interligar a bacia do Beberibe com a de Dois Irmãos, na altura de Passarinho. No entanto, o Dr. Imbeaux atestou que a bacia já era muito habitada e que não seria possível utilizar suas águas sem o uso de filtros. Além disso, o trajeto entre os dois vales, distantes em torno de $5,5 \mathrm{~km}$, era complicado e haveria necessidade de se construir três túneis e uma estação elevatória mecânica, chegando-se a conclusão de que essa adução seria bastante onerosa para o volume de água a se esperar. Dessa forma, o projeto de interligação entre as bacias do Beberibe e de Dois Irmãos foi rejeitado ${ }^{22}$.

Em fevereiro de 1924, a Companhia de Santa Thereza tomou empréstimo devido à necessidade de expandir os serviços contratados de fornecimento de

\footnotetext{
21 Costa, 1983.
}

22 Brito, 1915. 
água e luz elétrica a cidade de Olinda. Foi proposto para garantia do empréstimo que fosse dado todo o serviço de abastecimento de água e luz elétrica da cidade de Olinda, bem como o serviço de água do Arruda até a Caixa D’ água de Beberibe.

No primeiro terço do século $\mathrm{XX}$, ainda se refletia sobre a população olindense a precariedade dos serviços prestados pela Companhia de Santa Thereza, como se pode constatar em um comentário realizado por uma revista de grande circulação na época denominada $A$ Pilhéria:

"Os poderes públicos da vizinha cidade de Olinda estão na obrigação de tomar a sério este caso da Companhia Santa Thereza, fornecedora de água imprestável e luz deficiente para a antiga cidade balneária. Ninguém nesta terra desconhece o quanto de poderio e absolutismo exerce contra os seus clientes a antiga e sempre negligente empresa, fechando os ouvidos a todas as reclamações que lhe são endereçadas, partam ellas (sic) de onde partirem. Ultimamente, a população olindense, naturalmente exasperada de tanto reclamar e não ser atendida, tem tomado outras attitudes (sic) de protestos que têm ido até as portas do Sr. Claudino. (O Sr. Claudino, o concessionário dos servidores) procurando um remédio para os seus sofrimentos. E não se diga que esse protesto tem partido de pessoas sem responsabilidade que não medem as conseqüências (sic) de seus actos (sic). Antes, pelo contrário. Elle (sic) tem surgido do que Olinda tem de mais representativo, como aconteceu no último domingo. Cremos que já era tempo dos poderes públicos olharem com mais interesse para o caso, afim de evitar amanhã, acidentes mais desagradáveis” ${ }^{23}$.

A ineficiência da Companhia de Santa Thereza provocou fortes pressões, não só dos usuários, bem como da Prefeitura Municipal de Olinda que constantemente ameaçava rescindir o contrato com a empresa e tomar para si a responsabilidade do fornecimento de água e luz à cidade.

A partir de 1928 teve início uma verdadeira batalha judicial entre a Prefeitura de Olinda e a Companhia de Santa Thereza, que por várias vezes teve os seus bens sequestrados. Em 1933, com a morte do Sr. Claudino Leal, tornou-se praticamente insustentável a permanência da Companhia em questão. Em 23 de dezembro do mesmo ano, o então prefeito de Olinda, Sr. João Cabral Filho, baseado em sentença do Poder Judiciário, rescindiu o contrato com a Companhia e providenciou para que a municipalidade assumisse os seus serviços.

Dessa forma, encerrou-se o período de gestão privada no que concerne ao abastecimento de água e luz para a cidade de Olinda, e iniciou-se uma intervenção municipal, numa tentativa de melhorar a qualidade dos

\footnotetext{
${ }^{23}$ A Pilhéria, 1926, 1.
}

serviços prestados, bem como de aumentar a receita do município. Assim, foi criado o Serviço de Água e Luz de Olinda (SALO), que passou a utilizar as águas do rio Beberibe apenas para o abastecimento de sua população.

Em 1950, o Departamento de Saneamento do Estado de Pernambuco assinou um convênio com a Prefeitura de Olinda. Neste convênio, apesar de reconhecer que a captação das águas do rio Beberibe pertencia prioritariamente à municipalidade de Olinda, ficou estabelecido que a descarga excedente das necessidades da população olindense seria revertida para o suprimento do Recife. O rio Beberibe passou, então, a abastecer de água partes de Olinda e Recife, inclusive algumas áreas de morros da zona norte. Convém salientar que apesar do convênio em tela ter sido assinado em 1950, a utilização do Sistema Beberibe teve seu início já no ano de $1946^{24}$.

A captação original era feita numa pequena barragem de derivação situada em Caixa D’água, e uma estação elevatória, próxima à localidade de Passarinho. Mais adiante, em virtude da poluição provocada pela intensa urbanização da área, a captação foi transferida para local, $2 \mathrm{~km}$ a montante, denominado Pedacinho do Céu, retirando-se a água por gravidade. Para isso foi construída uma tubulação de concreto armado de 1000 mm de diâmetro ${ }^{25}$.

A ocupação desordenada dos morros e a retirada gradual de sua vegetação provocaram um aumento no processo erosivo, levando o rio Beberibe a constantes enchentes, no período outono-inverno, quando as chuvas são mais freqüentes. Em uma delas, a pequena barragem em Pedacinho do Céu, sofreu sérios danos e, como conseqüência, em 1985, voltou-se a fazer, provisoriamente, a captação em um ponto próximo à estação elevatória de Caixa D’ água. A água era elevada através de bombas submersíveis e encaminhada até uma caixa de areia, e daí, até o poço de sucção da estação elevatória.

No ano de 1968, o então Departamento de Saneamento do Estado de Pernambuco realizou uma série de estudos nos mananciais abastecedores da Região Metropolitana do Recife, com a finalidade de melhor aproveitá-los. Ao término desses estudos foi elaborado um documento intitulado Planejamento do Sistema de Abastecimento de Água da Área Metropolitana do Recife.

\footnotetext{
${ }^{24}$ SUDENE, 1968.

${ }^{25}$ COMPESA, 1986.
} 
Em relação à bacia do Beberibe, no documento em questão, concluiu-se que a referida bacia “está sendo invadida pela edificação de conjuntos residenciais, de modo que a poluição de suas águas está crescendo progressivamente; assim a conveniência da utilização desse manancial ficará muito reduzida em futuro não muito distante. Em face dessas considerações, julgamos preferível não incluir esse rio entre os mananciais disponíveis”26. Diante do exposto, pode-se perceber que, em finais da década de sessenta do século passado, o rio Beberibe já apresentava um quadro extremamente preocupante em relação à poluição de suas águas, bem como de sua viabilização como manancial.

Em 1971, no governo do Sr. Eraldo Gueiros Leite, foi criada a Companhia Pernambucana de Saneamento (COMPESA), órgão que até o presente momento assume a responsabilidade no abastecimento de água em Pernambuco. Dessa forma, inicia-se uma gestão estadual no manejo da bacia do Beberibe.

Em 1986, o Governo do Estado de Pernambuco, juntamente com a Secretaria do Saneamento, Obras e Meio Ambiente e a COMPESA elaboraram o Plano Diretor de Abastecimento de Água da RMR. Neste estudo, ao contrário do que aconteceu no planejamento de 1968, já anteriormente mencionado, o Sistema Beberibe não foi descartado, pois o objetivo do plano era o de aproveitar ao máximo os mananciais existentes.

Atualmente, a COMPESA mantém no rio Beberibe uma estação elevatória na Estrada de Caixa D’ água, como já citado anteriormente, próxima à localidade de Passarinho. A bacia hidrográfica a montante do ponto de captação é de $23 \mathrm{~km}^{2}$ e consegue retirar uma vazão de aproximadamente $450 \mathrm{l} / \mathrm{s}$, dependendo do nível do rio (Figura 9).

A captação é feita a fio d’água em Guabiraba, Recife, próxima a BR-101-Norte, e conduzida, por gravidade, em tubo de ferro de $600 \mathrm{~mm}$ de diâmetro, com extensão de $4.284 \mathrm{~m}$, até o poço de sucção da Estação Elevatória de Caixa D’Água.

Em seguida, a água é bombeada para duas estações de tratamento, uma situada no município de Olinda, denominada Estação de Tratamento de Caixa D’ água

\footnotetext{
${ }^{26}$ SUDENE, 1968, 141.
}

(ETA de Caixa D’ água), e outra para a Estação de Tratamento do Alto do Céu (ETA do Alto do Céu), no município de Recife.

Figura 9. Bacia do Beberibe: Área de Captação

\section{CONSIDERAÇÕES FINAIS}

O Sistema Beberibe, com uma disponibilidade hídrica de $450 \mathrm{l} / \mathrm{s}$, é pequeno se comparado aos outros sistemas abastecedores da Região Metropolitana do Recife como os de Pirapama (5.000 1/s), Tapacurá (3.100 l/s) e Botafogo (1.800 l/s). No entanto, o seu aproveitamento é justificável, pois as disponibilidades de água para fins industriais e para a alimentação humana, nas áreas que circundam o Grande Recife, são limitadas.

Na realidade, a população do Grande Recife já convive com problemas inerentes ao fornecimento de água, fato esse observado através de incentivos a uma política de racionamento e de aumentos de tarifas, além de campanhas difundidas pelos vários meios de comunicação procurando esclarecer a população na prática de se economizar água, evitando-se, dessa forma, o seu desperdício.

Atualmente, grande parte das águas do rio Beberibe e de seus afluentes está inserida no estágio de poluição total. Este estágio define-se de acordo com Barros et al. (1995), como aquele em que os corpos receptores tornam-se realmente afetados pela carga poluidora que recebem, expressa como sólidos em suspensão e 
consumo de oxigênio. O referido estágio normalmente ocorre durante o crescimento de áreas urbanas e o desenvolvimento industrial.

Essa situação é bem caracterizada a jusante da estação elevatória da COMPESA em Caixa D’ água (Olinda) até a foz conjunta com o Capibaribe, em $56 \mathrm{~km}^{2}$ de um total de $75,45 \mathrm{~km}^{2}$ de sua superfície. Nessa área, o rio Beberibe apresenta uma massa líquida escurecida e mal cheirosa, com o Índice de Qualidade de Água (IQA) variando de ruim a péssimo.

Vale a pena destacar a crescente ocupação das áreas de mananciais em função da concentração urbana. As regiões metropolitanas não mais crescem apenas no seu núcleo, mas se desenvolvem também em direção à periferia. Esta tendência está sendo ampliada, com deterioração dos mananciais.

Atualmente, as cabeceiras do rio Beberibe encontram-se relativamente preservadas. Entretanto, há um crescente adensamento populacional em dois pontos: a montante de Dois Irmãos, a partir da Estrada de Aldeia (PE-027), em direção às nascentes do Beberibe; e, mais recentemente, na estrada da Mumbeca (PE-016), a montante da Guabiraba, onde a concentração de moradias ocorre pela presença de clubes de campo, condomínios fechados horizontais, casas de eventos, enfim, tudo isso afeta a qualidade e a quantidade de água a ser ofertada pelo manancial em questão.

Diante do exposto, é de fundamental importância a manutenção do manancial Beberibe, através da ocupação ordenada de suas cabeceiras, procurando preservar as margens dos cursos de água. Para tanto, é necessário o respeito à legislação de proteção ambiental, uma fiscalização eficiente por parte dos órgãos competentes, além de um trabalho de conscientização ambiental da população, utilizando-se os meios de comunicação, escolas, sindicatos, associações de bairros etc. Em nosso entendimento, salvo melhor juízo, esses são condicionantes indispensáveis para que o usuário tenha acesso a uma água de boa qualidade e em abundância.

\section{REFERÊNCIAS}

Andrade, G. O. 1969: Montebelo: Os Males e Os Mascates. Recife, Universitária.

Andrade, M. C. 1979: Recife: Problemática de uma Metrópole de Região Subdesenvolvida. Recife, Universitária.

Brito, F. S. R. 1915: Saneamento de Recife: Descrição e Relatórios. Recife, Typographia do Jornal do Recife.

Campos, H. L. 1991: “A Bacia Hidrográfica do Beberibe: Um Enfoque Ambiental”, Dissertação (Mestrado em Geografia), Programa de Pós-Graduação em Geografia, Centro de Filosofia e Ciências Humanas, Universidade Federal de Pernambuco (UFPE), Recife.

Campos, H. L. 2003: "Processo Histórico de Gestão na Bacia Hidrográfica do Rio Beberibe: Uma Retrospectiva”, Tese (Doutorado em Geografia), Programa de Pós-Graduação em Geografia, Instituto de Geociências, Universidade Federal do Rio de Janeiro (UFRJ), Rio de Janeiro.

COMPESA (Companhia Pernambucana de Saneamento) 1986: Plano Diretor de Abastecimento de Água da Região Metropolitana do Recife. Caracterização do Sistema Existente. Recife, Secretaria do Saneamento, Obras e Meio Ambiente.

Costa, E. M. 1982: Expansão Urbana e Organização Espacial. Recife, Universitária.

Costa, F. A. P. 1983: Anais Pernambucanos. Recife, Fundação do Patrimônio Histórico e Artístico de Pernambuco - FUNDARPE, Diretoria de Assuntos Culturais.

Freyre, G. 1944: Olinda, $2^{\circ}$ guia prático, histórico e sentimental de cidade brasileira. Rio de Janeiro, José Olympio.

Gomes, E. T. A. 1997: "Recortes de Paisagens na Cidade do Recife: Uma Abordagem Geográfica”, Tese (Doutorado em Geografia), Programa de Pós-Graduação em Geografia, Departamento de Geografia, Universidade de São Paulo (USP), São Paulo.

Mello, J. A. G. 1988: Tempo dos Flamengos. Recife, Coleção Pernambucana, v. XV.

Pinto, E. 1949: História de uma Estrada-de-Ferro do Nordeste. São Paulo, José Olympio.

Pitta, S. R. 1950: História da América Portuguesa desde o ano de 1500 do seu descobrimento. Rio de Janeiro, W.M. Jackson, Coleção Clássicos Jackson, v. 30.

Revista A PILHÉRIA. 1926: "Recife", Jornal do Recife, VII (269), http://www.fundaj.gov.br/geral/didoc/pilheria/a_pilheria_1926_n269.pdf. Consulta realizada el 26 de junio de 2016.

SUDENE (Superintendência de Desenvolvimento do Nordeste) 1968: Planejamento do Sistema de Abastecimento D'água da Região Metropolitana do Recife. Recife, Departamento de Saneamento do Estado de Pernambuco. 